\title{
Analysis of left ventricular systolic function
}

\author{
Nelson B Schiller, Elyse Foster
}

A cross sectional echocardiographic image of the left ventricle is a trove of quantitative information that, in part, is extracted by manually tracing the borders of its walls and cavities. Investing the time required to learn and implement such quantification requires a conviction that extracting these data will generate information that allows confident identification and classification of the clinically relevant subtypes of left ventricular dysfunction. Furthermore, these data should assist in the design or selection of treatment algorithms that are also relatively specific to pathological classification.

\section{Importance of quantification in the two dimensional video environment}

Echocardiographic images, displayed as video images, are stored on analogue magnetic tape in real time for later interpretation and serial comparison. The use of video technology has the advantages and limitations of standard broadcast television. On the one hand, this medium is inexpensive, has high resolution, and is universally available. On the other hand, retrieval, review, and duplication are slow, and each copy or generation incrementally degrades the data. Furthermore, comparison of serial examinations is difficult because in order to be accurate, it requires side-by-side review stations of the same configuration (that is, cognate monitors) and identical echocardiographic instruments at the same depth settings operated by the same sonographer. In practice, these conditions are rarely met.

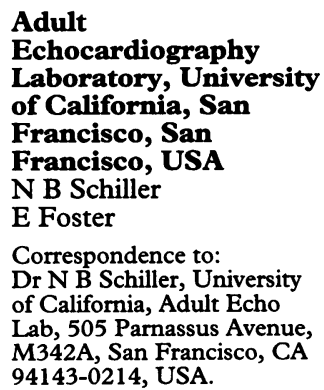

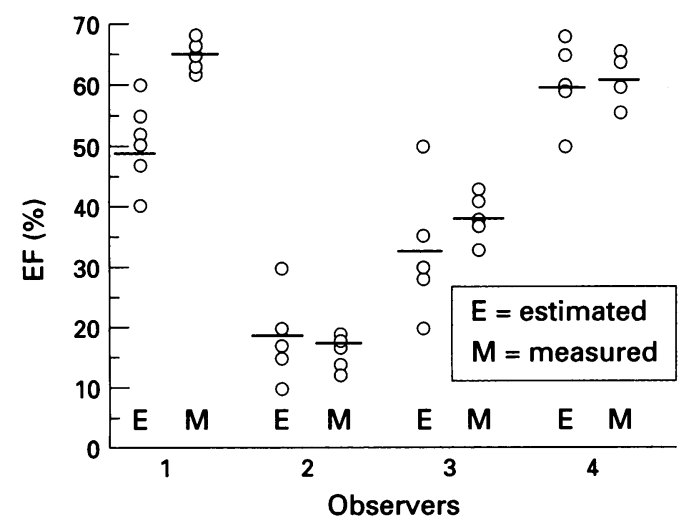

Figure 1 Ejection fraction estimated from a cross sectional echocardiogram by four observers of differing experience compared with triplicate manual measurements made by an experienced research sonographer. All studies were

technically good and were taken from a healthy individual, a patient with hypertension and two with cardiomyopathy. (Figure courtesy of Laura Kee).
Smaller laboratories often use the same instrument and sonographer but rarely use sophisticated review stations. Larger laboratories, with side-by-side review capabilities, often use a variety of instruments and several sonographers, each of whom may individualise the examination protocol. If a patient has serial examinations and each is acquired at a different depth setting, an enlarging heart can be made to appear smaller.

Faced with the dilemma posed by the video environment, we have adopted routine cross sectional quantification for all studies performed in our laboratory. In the years preceding this procedural change we made extensive use of cross sectional quantification of left ventricular function as a research tool. This experience led to the conviction that the information garnered from this practice had a major incremental value beyond the standard methods of qualitative evaluation or simple $M$ mode quantification.

Just before we introduced routine quantification, we performed a simple experiment in our laboratory that solidified its acceptance. At a routine reading session, five physicians of varying levels of experience (ranging from fellows with two months of training to attending level physicians or highly experienced echocardiographers with American Society of Echocardiography (ASE) Level III qualification $^{1}$ ) were shown four cases of excellent quality that had been measured by four experienced sonographers. Each was asked to record an "eyeball" estimation of the ejection fraction in each of the four cases. Figure 1 shows the results of this informal study. For each case, the left hand open circles represent the range of estimations and the right hand the measured values. Note that in two of the cases readers assigned normal values to a heart with depressed function and abnormal values to one that was quantitatively normal. Note also that the scatter of values was always less for the measured values than for estimated ones.

\section{Shortcomings of $M$ mode}

$M$ mode measurements became popular 20 years $\mathrm{ago}^{2-5}$ and, with the exception of the adoption of cross sectionally guided acquisition, ${ }^{6}$ have remained static. Their major shortcoming is that they rely on a single dimension of the left ventricular short axis to derive or extrapolate information about a threedimensional structure. When the ventricle is uniformly shaped with a long axis to short axis ratio of $2: 1, \mathrm{M}$ mode measurements are rela- 
tively reliable. However, most pathological states introduce regional asymmetry, alter the axes ratio towards unity, or both. Since volume is a cube function of dimension, errors are compounded in proportion to the extent of pathology. ${ }^{7}$ Additionally, the accuracy of $\mathrm{M}$ mode measurements also depends on clearly delineated boundaries and these are often ambiguous. It is not surprising that the normal and abnormal values for $M$ mode volume and mass often fail to conform to anatomical reality. ${ }^{7-9}$ Cross-sectionally measured volumes and mass, on the other hand, are similar to those obtained from angiography and pathology, allowing the direct clinical application of values obtained from their lengthy historical data base.

\section{Technical considerations in image acquisition}

In our laboratory, we have evolved a number of technical strategies aimed at fostering the quality and reproducibility of cross sectional images of the left ventricle. These tactics include patient position, imaging surface, operator position, control of breathing, image maximisation, reference to previous studies, biplane acquisition, digital acquisition, and on-line sonographer measurement. ${ }^{6}$

\section{IMAGING SURFACE AND PATIENT AND OPERATOR POSITION}

The best apical images are usually obtained by bringing the patient into steep left recumbency. This manoeuvre, identical to that used in precordial physical examination, brings the apex impulse location closest to the chest wall. In many subjects, however, left recumbency also brings the apex impulse close to the examining surface, and it becomes impossible to optimise transducer position. We avoid this by using mattresses that have a removable panel at the point where the apex impulse impinges on the examining surface. Examining tables with this feature are now commercially available. To take advantage of a fully exposed apex impulse window, we have found it advantageous to position the sonographer to the left of the patient. Such positioning has the added advantage of allowing the sonographer to sit comfortably while manipulating both transducer and controls and to direct the transducer through a full range of positions. This arrangement also allows the sonographer to avoid reaching over or resting on the patient, which is a disadvantage in the many laboratories that conduct examinations from the patient's right.

\section{IMAGE MAXIMISATION}

Acquiring images of the left ventricle for quantification requires awareness of the theoretical limitations of tomographic imaging. Since volumes are extrapolated from one or two orthogonal slices through the myocardium, each slice must pass through the largest dimensions of the chamber, to maximise the area subtended by the myocardium. This requirement is a weak link in the quantitative process because the choice of a maximal area is made qualitatively by the operator and may only approach but never truly reach a theoretically maximal slice. Three dimensional methods are now evolving that may overcome this limitation (see below).

\section{CONTROL OF BREATHING}

The heart changes position relative to the transducer during breathing. Patients should be asked to hold their breath when images intended for quantification are being acquired.

\section{DIGITAL ACQUISITION}

In our laboratory we determine left ventricular function from digitally acquired and stored single cardiac cycle cine loops. In this format, one screen of 8-12 systolic frames is divided into quadrants. In the upper quadrant, the long axis is recorded for reference and for wall motion analysis. The upper right quadrant contains the short axis used in combination with the apical views to determine left ventricular mass, and the lower panels contain the two and four chamber views (fig 2).

\section{REFERENCE TO PREVIOUS STUDIES}

An advantage of storing digital loops from prior studies is that they allow the sonographer to examine and use the old images to verify that the views in the new study are equivalent. It also assures the reader that the depth settings have been retained so that visual comparison is also possible.

\section{SONOGRAPHER MEASURES ON-LINE}

The measurements discussed below should be made at the bedside by the sonographer so that abnormal values will be immediately apparent and will stimulate a more complete examination aimed at amplifying and explaining the abnormality. This approach enhances the role of the sonographer. Also, examination submitted for interpretation will have more complete information and can be used to guide treatment and estimate prognosis.

\section{Measurements to use and their advantages}

The measurements that will be discussed here are left ventricular systolic and diastolic volume and ejection fraction. Left ventricular mass and left atrial volume are also routinely quantified in our laboratory and contribute to the interpretation of volume-based variables. The methods we use conform to the recommendations of the American Society of Echocardiography. ${ }^{6}$

\section{MEASUREMENT METHODOLOGY}

After completing the protocol discussed, the sonographer obtains cine loops that are suitable for quantification. They are measured with built-in electronic calipers which allow the operator precisely to apply or superimpose continuous lines delineating the endocardial and epicardial surface of chamber or wall to be quantified. These lines can measure a linear distance or can encompass an area. In quanti- 
Figure 2 Digitised images from a patient with mild aortic insufficiency (A) and one with HIVrelated cardiomyopathy (B) captured for the quantitative portion of routine examinations. In these four quadrant displays, the four images share a dynamic loop of 8-12 frames. By

convention, we display the long axis precordial view in the upper left, the short axis in the upper right, the four chamber view in the lower left, and the two chamber view in the lower right. Four images can be accommodated on one screen in their original size because the screen "real estate" has been efficiently apportioned by the digital acquisition system

(TomTec Freeland, Boulder, CO). In both examples, only the end systolic frames are shown. Both studies were acquired with the same instrument and measured by the same sonographer, and both were found to have the same end diastolic volume index of $75 \mathrm{ml} / \mathrm{m}^{2}$. In example $A$, a patient with mild aortic insufficiency and aortic root dilation, the end-systolic volume index was in the upper normal range at $28 \mathrm{ml} / \mathrm{m}^{2}$. The ejection fraction

(62\%) and left ventricular mass $\left(60 \mathrm{~g} / \mathrm{m}^{2}\right)$ were both within the normal range. In example $B$, the end systolic volume index is increased at $49 \mathrm{ml} / \mathrm{m}^{2}$ and the ejection fraction is reduced at $35 \%$. The mass is approximately 2.5 times normal at $170 \mathrm{~g} / \mathrm{m}^{2}$. The ejection fraction can be interpreted as being even more severely depressed than this value (35\%) would imply because an increased mass should decrease wall stress and augment ejection fraction. (Images courtesy of Daniel $S$ Francisco).
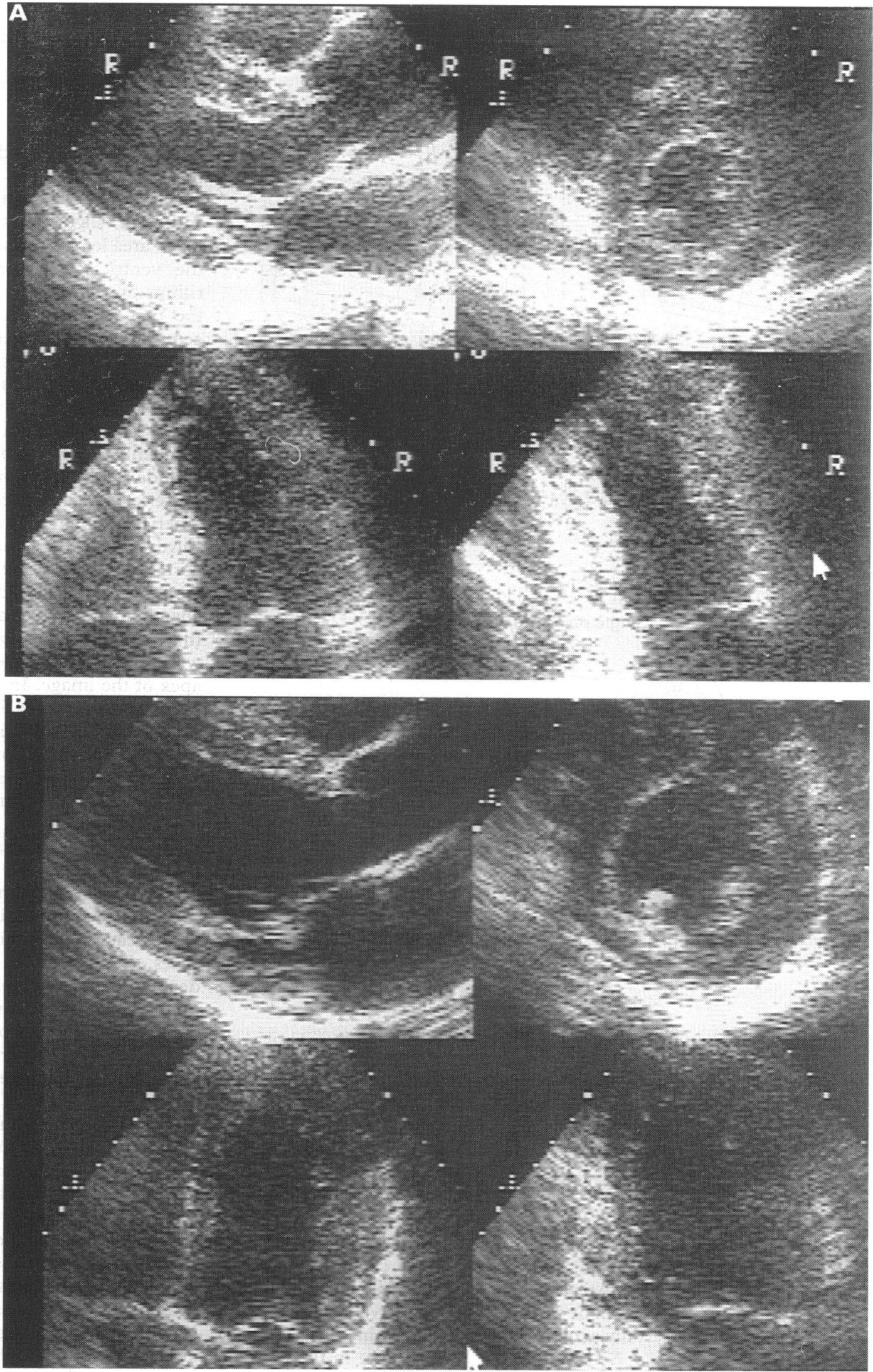

fying left ventricle volume, the endocardium is traced in both systole and diastole. The accuracy of the measurement depends on a clear notion of the precise location of the endocardial surface. This surface is often difficult to visualise as it is considerably lower in reflectance and more mobile than the brighter epicardium. Careful inspection of the segmental motion of the endocardium during the examination permits optimal gain settings and transducer frequency selection so that the selected cine loop is representative of the actual anatomy. A common failing in this step of the examination is the routine use of lower frequency imaging (that is, $2.5 \mathrm{MHz}$ ) throughout the examination. Although these transducers are ideal for Doppler examinations, low frequency images can be deceptively vivid 
Biplane method

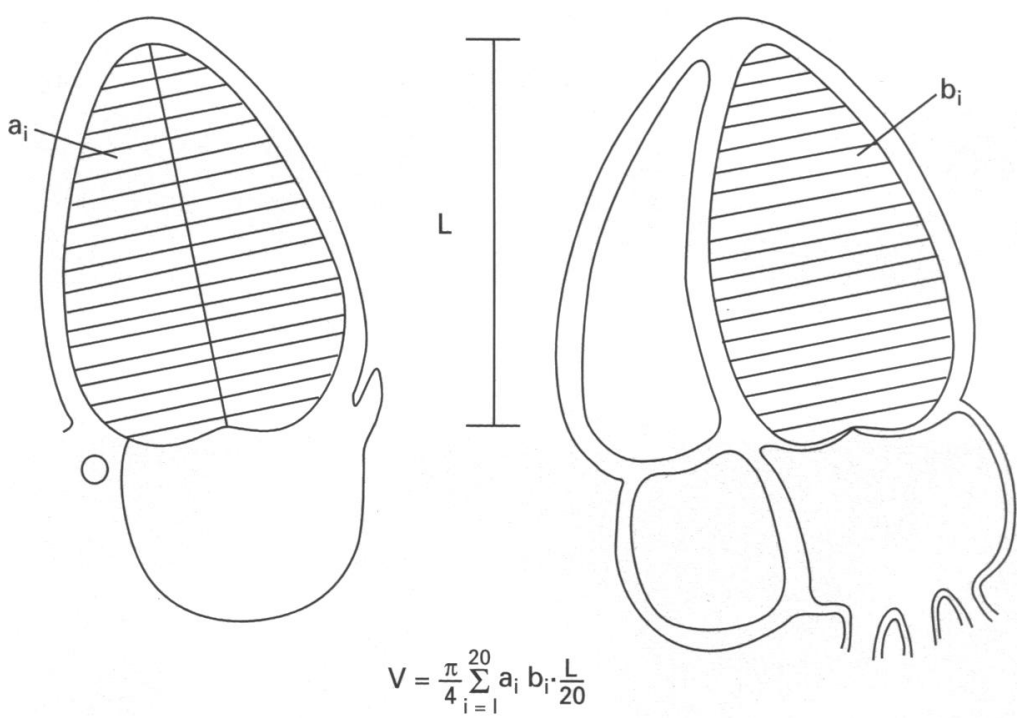

Single plane area length

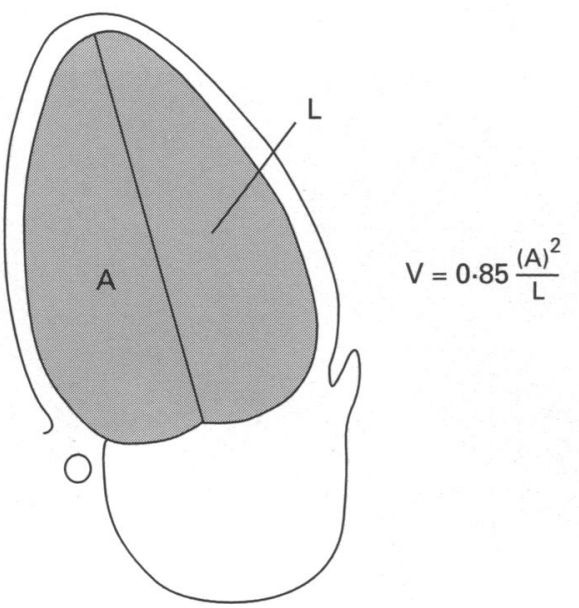

Figure 3 Left ventricular volume by biplane method of discs (modified Simpson's rule) and by single plane area length. The biplane method recommended by the ASE requires orthogonal two and four chamber apical views with nearly equal long axes and is considerably less sensitive to regionally remodelled hearts than the single plane method. shown below. If, on the other hand, the ventricle is symmetrical, the advantage of the biplane method is less. (By permission of the American Society of Echocardiography, $\mathrm{J}$ Am Soc Echocardiogr 1989;2:358-67.

while obscuring the delicate endocardium. Coaxing out the image of a coherent endocardial surface with a high frequency probe $(3.5$ $\mathrm{MHz}$ or higher) requires a level of skill that is only acquired through determined practice.

Selection of the precise time in the cardiac cycle for measurements is an important consideration. The end systolic frame is identified as the frame showing the smallest cavity occurring just before mitral opening and end diastole as the largest just before valve closure. Logically, the individual best suited to make the measurements is the echocardiographic sonographer, who should perform them at the time of acquisition. A beneficial byproduct of following this protocol is greatly improved appreciation and reproducibility of qualitative and quantitative (that is, by wall motion score) segmental ventricular function.

\section{MATHEMATICAL ALGORITHMS FOR COMPUTING} VOLUME AND MASS

The biplane method of discs (less precisely referred to as the modified Simpson's rule) is the two-dimensional algorithm that most closely predicts angiographic volumes. ${ }^{710-12}$ Although slightly less accurate, the single plane area length is also suitable, provided that the ventricle is symmetrical. ${ }^{10}$ These algorithms are applied to paired apical images of the two and four chamber apical views. In acquiring these images, the operator seeks to maximise their dimensions and to obtain views that are as close as possible to being orthogonal to one another. An acceptable four chamber view $^{13}$ should conform to certain criteria which augment reproducibility. These features include centering the image so that it is neither posteriorly or anteriorly canted. To avoid too anterior an interrogation, both atrioventricular valves should be seen without imaging the aorta. To avoid posterior malpositioning, the coronary sinus should not appear. The four chamber view should also pass through a plane that maximises the size of the right ventricle, while the left ventricle continues to form the apex of the image. In this view, the borders of the left ventricle are formed by the mid-point of the septum and the mid-lateral wall. The two chamber view should not include any portion of the right ventricle, aorta, or right atrium; its border-forming walls are the inferior and anterolateral.

Figure 3 is a diagram from the ASE standards document ${ }^{6}$ and represents (upper half) the apical two and four chamber views after the endocardium has been traced and the area of the cavity has been divided into 20 equal slices. The formula from which volume is derived is shown under these paired images. In practice, the instrument that allows the operator to trace the endocardial border of these images has been programmed to automatically combine these images and to represent the cavity as a stack of coins or discs. Automatically summing the individual volumes of each disc yields the total volume of the cavity at that point in the cardiac cycle. In the lower half of the diagram, a single plane image, in this case the two chamber view, has been analysed using a single plane area-length algorithm whose formula is given beside the image.

The method of discs depends on the two chambers being nearly equal in length. Measurement packages that are "bundled" into echocardiographic instruments differ from one another in how inequality of the axis, when encountered, is handled. For example, one manufacturer automatically assigns the longer of the two lengths to both, on the assumption that echocardiography images inherently underestimate true dimensions and thus that the longer dimension is correct.

Figure 4 shows clinically acquired paired orthogonal two chamber (lower half) and fourchamber (upper half) views with diastole to the left and systole to the right. ${ }^{14}$ The sonogra- 
Figure 4 Appearance of the digitised two and four chamber views after the sonographer has traced the endocardium and has instructed the computer to apply the method of discs for calculating systolic and diastolic left ventricular volume.
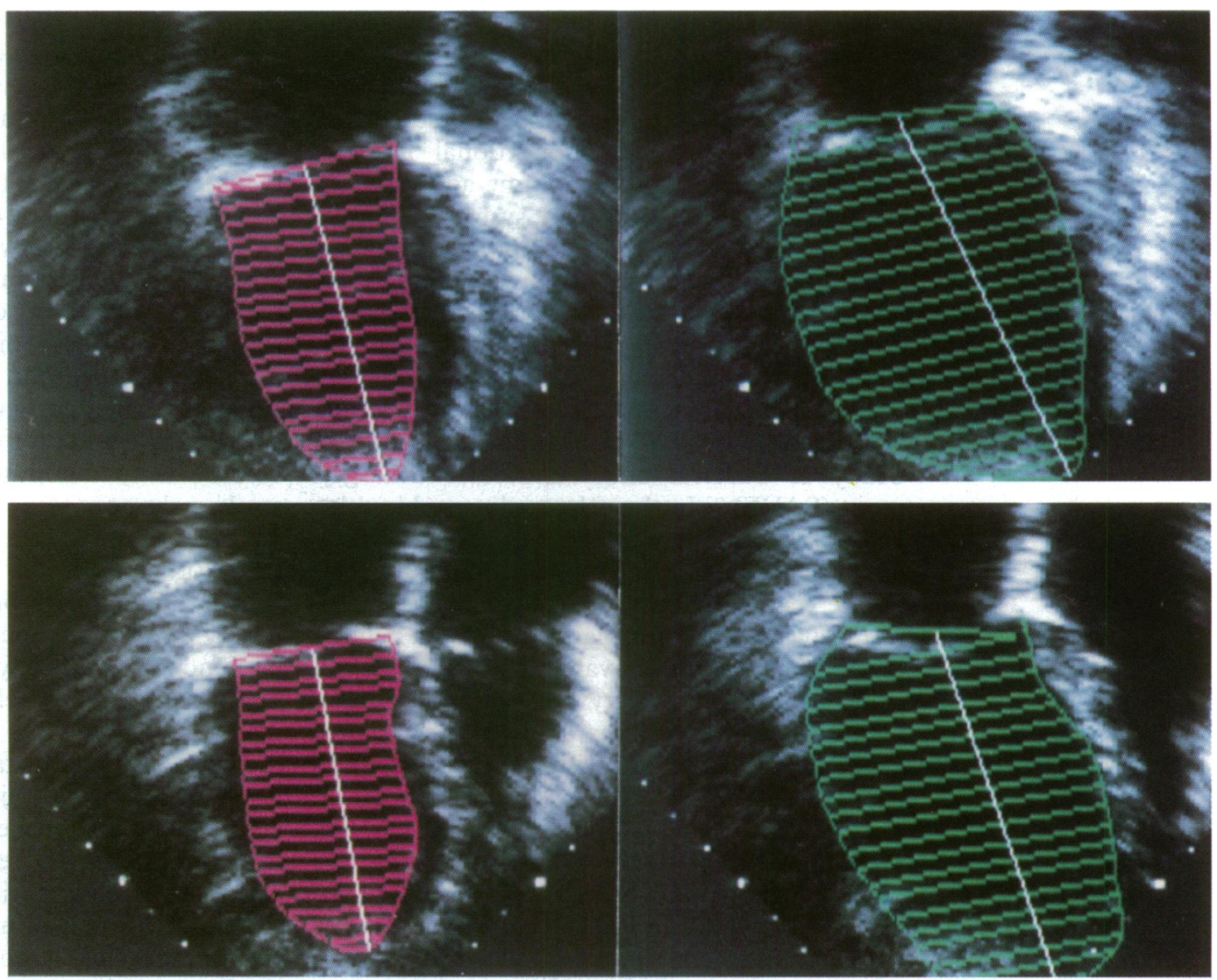

pher has traced the endocardial outline in each phase of the cardiac cycle and the computer has partitioned the ventricle into 20 equal slices. Left ventricular mass computed from cross sectional images is more reproducible and anatomically rational than $M$ mode values. However, the usefulness of all mass determinations is limited by their relatively wide standard deviations. With the most robust methods, a change from a previous study or a deviation from normal of at least $35 \mathrm{~g}$ is required to reach the $95 \%$ confidence interval that indicates that the change or abnormality is real. The most reliable algorithms for determining mass are the truncated ellipsoid or area length; both are recommended by the ASE. ${ }^{615}$ Figure 3 shows the echocardiographic images used for these algorithms and their formulae.

\section{END SYSTOLIC VOLUME}

End systolic volume is a powerful measurement. Its value has been established in the angiographic literature ${ }^{16-18}$ and its pathophysiological rationale solidly established. ${ }^{19} 20$ This is a unique measurement because, quoting Sagawa et $a l,{ }^{19}$ " ". . . the ventricular pressure/ volume ratio at end-systole is relatively insensitive to cardiac loading and varies greatly in response to changes in ventricular contractility." That such a measurement is clinically useful is hardly surprising. Therefore it is fortunate that of all echocardiographic volumebased measurements, it is the easiest to make and the most reproducible (fig 5). ${ }^{21}$

In our clinical practice, routine cross sectional echocardiographic measurement of the end systolic volume index gives values that are very similar to angiography, allowing us to use directly prognostic data from the angiography literature. For example, in 1980 , Borow et al ${ }^{18}$ showed that complications occurring after surgery for aortic and mitral regurgitation were confined to patients with an end systolic angiographic volume index of greater than 66 $\mathrm{ml} / \mathrm{m}^{2}$. Hammermeister et al, ${ }^{16}$ using angiographic data in coronary disease, showed that an end systolic volume index of greater than $45 \mathrm{ml} / \mathrm{m}^{2}$ identified a group with almost 150 deaths per 1000 patient years. End systolic indices below $45 \mathrm{ml} / \mathrm{m}^{2}$ were associated with a death rate of less than 50 per 1000 patient years. These impressions were confirmed in a

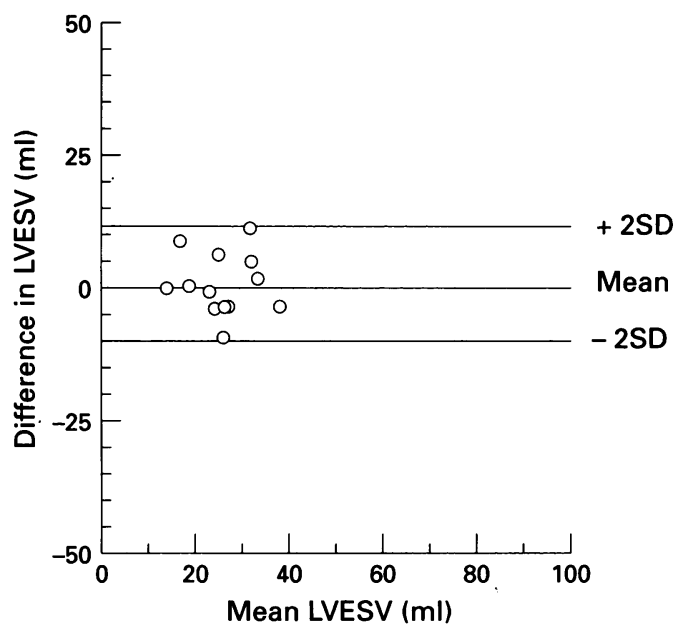

Figure 5 Reproducibility of end systolic volume. In this study of variability, a subject was studied on two separate occasions with no intervening clinical change. The mean value of the two studies (each measured and performed by two technicians) is shown on the abscissa plotted against the mean difference among the measurements. Note that a change of little more than $10 \mathrm{ml}$ between studies is likely to indicate a real change in systolic volume. (Courtesy of Helmut Kuecherer). 
more recent study by White et al, ${ }^{17}$ who also performed ventriculography in over 600 patients after myocardial infarction. End systolic volume was a more powerful predictor of mortality by the Cox proportional hazards model than end diastolic volume and ejection fraction $\left(\chi^{2}=82.9\right.$ for end systolic volume, 59.0 for end diastolic, and 46.6 for ejection fraction). Furthermore, stepwise regression showed that after accounting for end systolic volume, the other variables showed no additional predictive value.

The clinical utility of end systolic volume was recently reinforced by the results of the Study of Survival and Ventricular Enlargement (SAVE) ${ }^{22}$ In the echocardiographic substudy 512 subjects were studied about 11 days after myocardial infarction and 420 survivors at one year. ${ }^{23}$ Patients were randomly assigned to receive captopril or placebo, and the behaviour and predictive value for survival of echocardiographic cavity area was computed. Captopril treatment was associated with less cavity enlargement and with improved survival (risk reduction of $35 \%$ ). Of the indices of enlargement, end systolic size (area) was the most powerful predictor of survival.

In summary, end systolic left ventricle volume and volume index are easy to measure, reproducible, and the most powerful predictors of cardiovascular events in several cardiac diseases. If an echocardiography laboratory offering "basic services" with little time for "advanced measurements" were to choose one simple measurement, it should be end systolic volume index. An effective argument against this recommendation would be difficult to mount.

\section{END DIASTOLIC VOLUME}

End diastolic volume is also a valuable but less powerful predictor of cardiac events. Nonetheless, most of the studies cited above indicate that it has predictive value. The major technical problem with obtaining this variable is that the endocardium is more difficult to image at end diastole. A large apical artefact commonly obscures the apical lateral wall, and atrial contraction may introduce a rapid relocation of the endocardial boundary into that artefact. Whereas the contracted boundaries of

Figure 6 Reproducibility of end diastolic volume. The same experiment described in the figure 5 legend is applied to end diastolic volume. Note that the confidence intervals are about double those for end systolic volume. A change of more than $20 \mathrm{ml}$ is needed before it can be ascribed to a real anatomical variation rather than to measurement error. (Courtesy of Helmu Kuecherer).

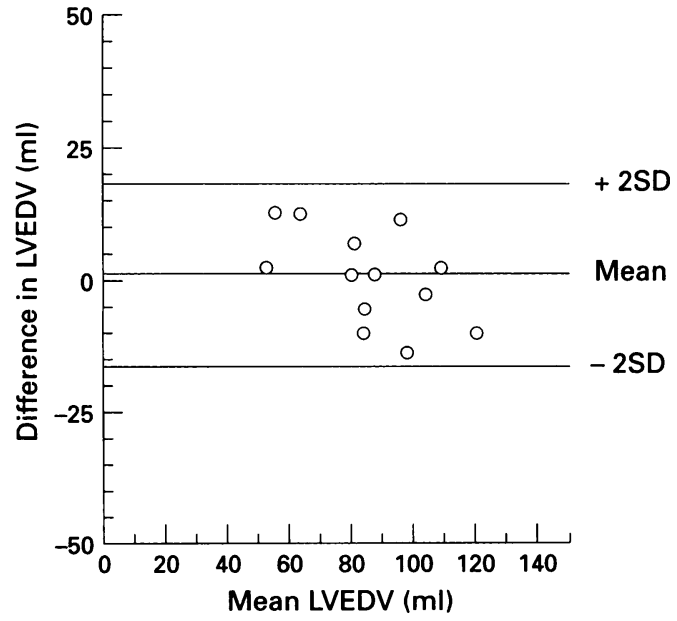

the end systolic endocardium are relatively easy to appreciate, accurate and reproducible digitisation of the diastolic outline is more challenging. In our studies of reproducibility, ${ }^{21}$ end diastolic volume had relatively wide $95 \%$ confidence intervals (about $\pm 25 \mathrm{ml}$ ) (fig 6). This characteristic of echocardiographic measurement of diastolic volume means that a relatively large change in cardiac size is required before the measured change can be regarded as being beyond the limits of statistical variation. Thus rather than providing a robust measure of left ventricular status, the most compelling reason for computing end diastolic volume is to compute ejection fraction and stroke volume.

\section{EJECTION FRACTION}

Ejection fraction is probably the most commonly discussed clinical index of left ventricular function. Ironically, it is usually estimated visually and only rarely measured. It is likely that a preponderance of physicians interpreting echocardiograms take pride in their skill at visual estimation of ejection fraction and just as unlikely that their esteem with their skill is ever diminished by testing it against a reference standard. Experience with a test similar to the one we conducted (fig 1) would, we believe, provide a potent incentive for routinely measuring end systolic and end diastolic volumes and calculating their ratio-that is, the ejection fraction (EDV-ESV/EDV).

Despite the variability of diastolic volume measurement, ejection fraction has been shown to be highly reproducible ${ }^{21}$ (fig 7). A change of as little as $7 \%$ falls outside two standard deviations for measurement error.

Although ejection fraction is not as predictive of prognosis as end systolic volume, it provides highly useful prognostic data. For example, in the GISSI-2 trial of more than 10000 survivors of myocardial infarction treated with thrombolytic agents, an ejection fraction of less than $40 \%$ was a powerful predictor of a sharply increased six month mortal-

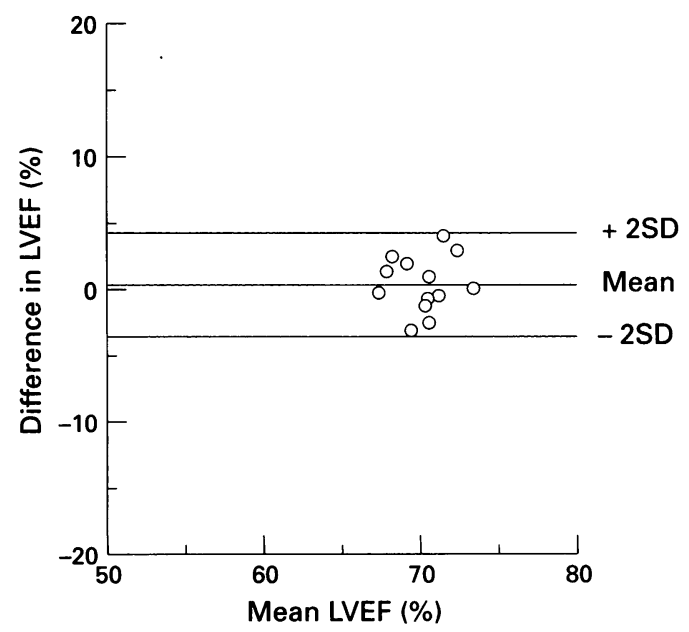

Figure 7 Reproducibility of ejection fraction. In this study of variability, a subject was studied by two sonographers on each of two occasions. The variability introduced by changing sonographers is illustrated. Note that a change of as little as $7 \%$ in ejection fraction can be ascribed to a as little as $7 \%$ in ejection fraction can be ascribed to
change in contractile function. (Courtesy of Helmut Kuecherer). 
ity. ${ }^{24}$ In White et al's angiographic study of survival after myocardial infarction, ${ }^{17}$ combining the most powerful predictor of survival, end systolic volume index, with ejection fraction identified the subgroups who differed most strikingly in adverse prognosis.

In patients with heart failure, myocardial, or valve diseases, knowledge of the ejection fraction can be integrated with clinical and haemodynamic data to provide a rational basis for selecting treatment (see below).

The following normal values for left ventricular volume and mass and left atrial volume are derived from several studies ${ }^{61025-32}$ and may serve as a reference for clinically measured studies. These data are expressed as means, both raw and corrected for body surface area. The term " 0.9 UCB" is the $90 \%$ upper confidence bound of the 95 th percentile and is nearly equivalent to a value of two standard deviations from the mean. (A discussion of left ventricular mass and left atrial volume is beyond the scope of this discussion of systolic function but both are routinely measured in our laboratory and will be referred to in the discussion of clinical algorithms.):

End diastolic volume

Male: $111 \mathrm{ml}(156=0.9 \mathrm{UCB})$, index 58 $\mathrm{ml} / \mathrm{m}^{2}(80)$

Female: $80 \mathrm{ml}(105=0.9 \mathrm{UCB})$, index 50 $\mathrm{ml} / \mathrm{m}^{2}(66)$

End systolic volume

Male: $34 \mathrm{ml}(58=0.9 \mathrm{UCB})$, index $18 \mathrm{ml} / \mathrm{m}^{2}$ (30)

Female: $29 \mathrm{ml}(50=0.9 \mathrm{UCB})$, index 18 $\mathrm{ml} / \mathrm{m}^{2}$ (32)

\section{Ejection fraction}

$61 \pm 10 \%$

Left ventricular mass

Male: $135 \mathrm{~g}(183=0.9 \mathrm{UCB})$, index $71 \mathrm{~g} / \mathrm{m}^{2}$ (95)

Female: $99 \mathrm{~g} \quad(141=0.9 \quad$ UCB $)$, index $62 \mathrm{~g} / \mathrm{m}^{2}(89)$

Volume/mass ratio: $0.83(1 \cdot 12=0.9 \mathrm{UCB})$

Left atrial volume

Male: $41 \mathrm{ml}(65=0.9 \mathrm{UCB})$, index $21 \mathrm{ml} / \mathrm{m}^{2}$ (32 $=0.9$ UCB)

Female: $32 \mathrm{ml}(52=0.9 \mathrm{UCB})$, index 21 $\mathrm{ml} / \mathrm{m}^{2}(32=0.9 \mathrm{UCB})$

\section{Simple confirmatory methods}

One of the strengths unique to echocardiography is the breadth of confirmatory data that is generated during a standard examination. In making a determination of systolic function the interpreting physician can draw on many sources for reinforcing information. These include $\mathrm{M}$ mode variables such as mitral $\mathrm{E}$ point septal separation, ${ }^{33}$ aortic root motion ${ }^{34}$ and, of course, the basic dimensions and fractional shortening of the minor axis. Mitral septal separation, if greater than $7 \mathrm{~mm}$, is indicative of an ejection fraction below $45 \%$. As such, this "eyeball index" can quickly identify a patient with coronary disease as belonging to a higher risk category. E-Point separation, being a global index, can also confirm or raise doubt about a measured ejection fraction that seems to differ from visual interpretation of contractility. Aortic root motion, normally greater than $14 \mathrm{~mm}$ during systole, is associated with a decreased stroke volume. If, for example, the ejection fraction is normal and aortic root motion is depressed, decreased preload may be inferred.

In the cross sectional two and four chamber apical views, the descent of the cardiac base is an important visual clue to myocardial dysfunction. ${ }^{35}{ }^{36}$ The annulus normally moves 15 $\mathrm{mm}$ towards the stationary apex during systole. This motion represents the shortening of the longitudinal muscles and is an early indicator of myocardial dysfunction. It is a very important component of the change in cavity dimensions during systole, and it is not represented in any of the short axis $\mathbf{M}$ mode indices of function. The motion of the cardiac base can often be visualised even though a study is technically poor. The descent of the base also aids interpretation of ventricles for which the contractile appearance appears unexpectedly low or the ejection fraction data are discrepant with other data. For example, athletic individuals with slow heart rates may appear to have mildly depressed ventricular function. Inspection of the cardiac base will invariably show vigorous motion and this observation will dispel the notion of abnormality. On the other hand, individuals with early cardiomyopathy may appear to have normal radial shortening but inexplicably low measured ejection fractions. Here the descent of the base appears depressed and is often the first sign of cardiac dysfunction. Evaluation of the size and respiratory response of the inferior vena cava is indispensable, providing indirect information about the influence of left ventricular function on right ventricular filling pressure.

Doppler data also provide powerful ancillary information about systolic function. For example, we routinely obtain flow velocity signals from the left ventricular outflow tract and pulmonary artery. Planimetry of these signals provides a flow velocity integral or stroke distance that can serve as a complementary value for establishing the validity of measured stroke volume. In our practice, this information also alerts us to high cardiac output states such as hepatic failure, sepsis, or anaemia. Other Doppler information that is indispensable in the routine echocardiographic evaluation of systolic function includes the recognition of raised filling pressures by diastolic inflow patterns from the mitral valve or pulmonary veins, raised pulmonary pressures from increased tricuspid insufficiency jet velocity, and the rate of rise of left ventricular pressure measured by transoesophageal echocardiography of acceleration of the mitral regurgitation jet.

\section{Advances in quantification}

The techniques discussed for calculating left 
Clinical algorithms for direct application of haemodynamic classification of left ventricular status by quantitative cross sectional and Doppler echocardiography

\begin{tabular}{|c|c|c|c|c|c|c|c|c|c|}
\hline $\begin{array}{l}\text { Haemodynamic } \\
\text { category }\end{array}$ & LVEF (\%) & LVESVI & $L V E D V I$ & $L V O T V T I$ & Mitral $E / A$ & $\begin{array}{l}\text { Pulmonary } \\
\text { vein } \\
\text { flow }\end{array}$ & $\begin{array}{l}\neq P A S P \\
(T R V E L) \\
(m m H g)\end{array}$ & $I V C$ & Treatment \\
\hline Normal & $>55$ & $18 \mathrm{ml} / \mathrm{m}^{2}$ & $55 \mathrm{ml} / \mathrm{m}^{2}$ & $20 \mathrm{~cm}$ & $\begin{array}{l}1.2 \text { (or less, A-DOM, } \\
\text { if }>\text { age } 60 \text { ) }\end{array}$ & $S>D$ & $<30$ & $\begin{array}{l}<18 \mathrm{~mm} \text {, } \\
\text { respiratory } \\
\text { collapse }\end{array}$ & None \\
\hline $\begin{array}{l}\text { Hyperdynamic/ } \\
\text { high output }\end{array}$ & NL to increase & Decrease & NL & $>20$ & $\begin{array}{l}1 \cdot 2 \text { (or less, A-DOM, } \\
\text { if }>\text { age } 60 \text { ) }\end{array}$ & $S>D$ & $<30$ & $\begin{array}{l}<18 \mathrm{~mm} \text {, } \\
\text { respiratory } \\
\text { collapse }\end{array}$ & $\begin{array}{l}\text { Underlying } \\
\text { condition }\end{array}$ \\
\hline Hypovolaemia & Increase & Decrease & Decrease & $\begin{array}{l}<20 \\
\text { (HR increase) }\end{array}$ & $\begin{array}{l}1 \cdot 2 \text { (or less, A-DOM, } \\
\text { if }>\text { age } 60 \text { ) }\end{array}$ & $S \gg D$ & $<25$ & $\begin{array}{l}\text { Small, } \\
\text { spont resp } \\
\text { collapse }\end{array}$ & $\begin{array}{l}\text { Replete } \\
\text { intravascular } \\
\text { volume }\end{array}$ \\
\hline Mild LV failure & Mild decrease & $\begin{array}{l}\text { Upper NL } \\
\text { to increase }\end{array}$ & $\begin{array}{l}\text { Upper NL } \\
\text { to increase }\end{array}$ & $\begin{array}{l}\text { Mild decrease } \\
(16-18)\end{array}$ & $\mathrm{E} \mathrm{DOM}(>1 \cdot 2)$ & $\mathrm{S}<\mathrm{D}$ & $>30$ & $\begin{array}{l}\text { NL to } \\
\text { mild } \\
\text { plethoric }\end{array}$ & $\begin{array}{l}\text { Digoxin } \\
\text { Dluretics, } \\
\text { vasodilator } \\
\text { (eg, ACE } \\
\text { inhibitor) }\end{array}$ \\
\hline $\begin{array}{l}\text { Moderate/severe } \\
\text { LV failure }\end{array}$ & $\begin{array}{l}\text { Moderate } \\
\text { decrease (30-45) }\end{array}$ & $>30$ & $>75$ & $\begin{array}{l}\text { Moderate } \\
\text { decrease }\end{array}$ & $\operatorname{EDOM}(\gg>1 \cdot 2)$ & $\mathrm{S} \ll \mathrm{D}$ & $>50$ & $\begin{array}{l}\text { *Plethoric, } \\
\text { poor } \\
\text { collapse } \\
\text { with } \\
\text { respiration }\end{array}$ & $\begin{array}{l}\text { Digoxin } \\
\text { diuretics, } \\
\text { vasodilator } \\
\text { (eg, ACE } \\
\text { inhibitor) } \\
\text { depends } \\
\text { on BP }\end{array}$ \\
\hline $\begin{array}{l}\text { Cardiogenic } \\
\text { shock }\end{array}$ & $\begin{array}{l}\text { Severe decrease } \\
(<10-30)\end{array}$ & $>45$ & $>100$ & $\begin{array}{l}\text { Severe } \\
\text { decrease }(<10)\end{array}$ & $\begin{array}{l}\text { E DOM (often no a } \\
\text { wave) }\end{array}$ & $\begin{array}{l}\mathrm{S} \ll \mathrm{D} \text { or } \\
\text { systolic absent }\end{array}$ & $>60$ & $\begin{array}{l}\text { ^Plethoric, } \\
\text { collapse } \\
\text { poor with } \\
\text { respiration }\end{array}$ & $\begin{array}{l}\text { Inotropic } \\
\text { counter- } \\
\text { pulsation } \\
\text { etc }\end{array}$ \\
\hline
\end{tabular}

$\mathrm{HR}=$ heart rate, $\mathrm{LV}=$ left ventricle, $\mathrm{EF}=$ ejection fraction, $\mathrm{ESV}=$ end systolic volume, $\mathrm{ED}=$ end diastolic volume, $\mathrm{I}=$ indexed for body surface area, $\mathrm{LVOT}=$ left ventricular outflow tract, VTI = velocity time integral of the Doppler flow signal from the LVOT, E/A = ratio of peak velocity of the mitral inflow early filling left ventricular outflow tract, VTI = velocity time integral of the Doppler flow signal from the LVOT, E/A = ratio of peak velocity of the mitral inflow early filling wave $(E)$ to the late active filling wave $(A), P A S P=$ pulmonary systolic pressure, TR VEL $=$ peak velocity of the tricuspid regurgitation jet, IVC $=$ inferior vena cava, $S=$ systolic wave of the pulmonary venous inflow Doppler signal, $D=$ diastolic wave of the pulmonary venous inflow Doppler signal, NL $=$ within normal limits, $\mathrm{E} D O M=$ the mitral inflow early wave $(\mathrm{E})$ has a higher velocity than the late atrial $(\mathrm{A})$ filling wave, $\mathrm{A} \mathrm{DOM}=$ the mitral inflow late valve $(\mathrm{A})$ has a higher velocity than the early wave $(E)$.

* May be normal if RV function remains normal

$\ddagger\left(4 \times\right.$ TR velocity ${ }^{2}+$ IVC)

ventricular systolic function require manual planimetry of the endocardial and epicardial borders. Over the past 15 years we have depended heavily on these measurements in the interpretation of routine echocardiograms. This experience has been both rewarding and frustrating. Foremost among their problems have been issues of precision and reproducibility arising from the free-hand acquisition of images and the limited sample of the ventricle from which volume extrapolations are made. A particularly promising approach to avoiding these problems has been proposed by groups who are developing three-dimensional systems for ventricular measurement. ${ }^{37-41}$ In these systems, several gated images of the left ventricle are acquired from a variety of windows. During image acquisition, the position of the transducer is spatially tracked by a locating device and the group of images obtained can be combined into a single data set. The image slices comprising this set of data are manually traced and digitally reconstructed and the cavity or wall volume (that is, mass) is calculated from that reconstruction. The correlations with reference standard magnetic resonance imaging and the internal reproducibility have proved superior to standard cross sectional imaging. As the technique has evolved, the image processing and measurement time has fallen to under 15 minutes. It remains to be seen if these prototypes will evolve into devices suitable for adoption into standard practice but their success could provide cardiologists with a cost-effective means of detecting subtle degrees of dysfunction or therapeutically induced changes in ventricular morphology and performance.

Another advance in quantitative technology that may accelerate application of left ventricu- lar quantification is automated border detection based on back scatter. The endocardial to blood pool border is identified and tracked. After delineation of the region of interest, continuous curves relating time to cross sectional area and volume are generated. At the present time, the feasibility and accuracy of this evolving technique are more dependent on image quality than the manual methods. Ultimately it will be directly applied to three dimensional quantification. $^{42}$

\section{Trends in data display and storage}

Echocardiography, along with most other cardiac and non-cardiac imaging techniques, is about to undergo a revolution in the way images are acquired, stored, and manipulated. As discussed, video tape is a linear analogue storage medium that thwarts retrieval, analysis, manipulation, and distribution of images. Several commercial and research groups are developing digital storage devices that allow undegraded echocardiographic images to be stored, rapidly retrieved, and compared. Working with the prototype of one of these systems, we compared the time required for a physician to read a digitally stored study with that required to interpret the same study on video tape. We were able to reduce the reading time from 11 minutes to four minutes. The time reduction occurred because the sonographer was careful to record only the most relevant images and because the contiguous loop format allowed sufficient time to examine all aspects of each image without having to repeatedly rewind the tape. Comparisons were improved because it was possible to manipulate the images. Once in digital format, it will be possible for the images to be saved in the 
hospital archives and retrieved at remote sites. These remote viewing locations will include the operating room, the critical care units and, perhaps most importantly, the physician's office and home.

\section{Clinical algorithms for these data}

The table is a compilation of echocardiography/Doppler variables that can be recruited to assist in the interpretation of clinical syndromes. The table is somewhat idealised and may not always reflect a given clinical situation. Moreover, the distinction between and among categories is often blurred and protean. Similarly, treatment recommendations based on these algorithms are presented in the broadest possible terms and their use must be tempered by clinical imperatives.

\section{Is quantification of left ventricular function recommended for every laboratory?}

As a diagnostic technique, echocardiography has relentlessly evolved. Even the most humble and austere laboratory, dedicated to providing only a minimum of service, eventually accedes to this evolution. We recommend that all laboratories, however modest, adopt cross sectional quantification of left ventricular function because it increases the cost-effectiveness of the procedure by improving sonographer skills and performance, by increasing diagnostic resolution, and by refining therapeutic decisions.

1 Pearlman AS, Gardin JM, Martin RP, Parisi AF, Popp RL, Quinones MA, et al. Guidelines for physician training in transesophageal echocardiography: recommendations of the American Society of Echocardiography Committee for Physician Training in Ech

2 Corya BC, Rasmussen S, Knoebel SB, Feigenbaum H. Mmode echocardiography in evaluating left ventricular function and surgical risk in patients with coronary artery disease. Chest 1977;72:181-5.

3 Fortuin NJ, Hood W Jr, Craige E. Evaluation of left ventricular function by echocardiography. Circulation 1972 46:26-35.

4 Kisslo J, Wolfson S, Ross A, Pasternak R, Hammond G, Cohen LS. Ultrasound assessment of left ventricular function following aortocoronary saphenous vein bypass grafting. Circulation 1973;3 suppl 3:156-61.

5 McDonald IG, Feigenbaum H, Chang S. Analysis of left ventricular wall motion by reflected ultrasound. Application to assessment of myocardial function. Application to assessment

6 Schiller NB, Shah PM, Crawford M, DeMaria A, Devereux R, Feigenbaum H, et al. Recommendations for quantitation of the left ventricle by two-dimensional quantitation of the left ventricle by two-dimensional graphy Commitree on Standards, Subcommittee on graphy Committee on Standards, Subcommittee on Quantitation of Two-Dimensional

7 Schiller NB, Acquatella H, Ports TA, Drew D, Goerke J, Ringertz $\mathrm{H}$, et al. Left ventricular volume from paired biplane two-dimensional echocardiography. Circulation 1979;60.547-55.

8 Germain PRG, Kastler B, Mossard JM, Bareiss P, Sacrez A. Inter-study variability in left ventricular mass measurement. Comparison between M-mode echography and MRI. Eur Heart $\mathcal{F}$ 1992;13:1011-9.

9 Collins HW, Kronenberg MW, Byrd B III. Reproducibility of left ventricular mass measurements by two-dimensional and M-mode echocardiography. $\mathcal{F}$ Am Coll Cardiol 1989;14:672-6.

10 Silverman NH, Ports TA, Snider AR, Schiller NB, Carlsson E, Heilbron DC. Determination of left ventricular volume in children: echocardiographic and angiographic comparisons. Circulation 1980;62:548-57.

11 Folland ED, Parisi AF, Moynihan PF, Jones DR, Feldman $\mathrm{CL}$, Tow DE. Assessment of left ventricular ejection fraction and volumes by real-time, two-dimensional echocardiography. A comparison of cineangiographic and radionuclide techniques. Circulation 1979;60:760-6. 12 Starling MR, Crawford MH, Sorensen SG, Levi B, Richards KL, O"Rourke RA. Comparative accuracy of apical biplane cross-sectional echocardiography and gated equilibrium radionuclide angiography for estimating left ventricular size and performance. Circulation 1981;63:1075-84.

13 Silverman NH, Schiller NB. Apex echocardiography. A two-dimensional technique for evaluating congenital heart disease. Circulation 1978;57:503-11.

14 Schiller NB. Two-dimensional echocardiographic determination of left ventricular volume, systolic function, and mass. Summary and discussion of the 1989 recommendations of the American Society of Echocardiography. dations of the American Society of
Circulation 1991;84 suppl 3:1280-7.

15 Schiller NB. Considerations in the standardization of measurement of left ventricular myocardial mass by twosurement of left ventricular myocardial mass by two-
dimensional echocardiography. Hypertension 1987;9: III-33-5.

16 Hammermeister KE, DeRouen TA, Dodge HT. Variables predictive of survival in patients with coronary disease. Selection by univariate and multivariate analyses from the clinical, electrocardiographic, exercise, arteriographic, and quantitative angiographic evaluations Circulation 1979;59:421-30.

17 White HD, Norris RM, Brown MA, Brandt PW, Whitlock RM, Wild CJ. Left ventricular end-systolic volume as the major determinant of survival after recovery from myocardial infarction. Circulation 1987;76:44-51.

18 Borow KM, Green LH, Mann T, Sloss LJ, Braunwald E Collins JJ, et al. End-systolic volume as a predictor of postoperative left ventricular performance in volume overload from valvular regurgitation. $A m$ F Med 1980; 68:655-63.

19 Sagawa K, Suga H, Shoukas AA, Bakalar KM. End-systolic pressure/volume ratio: a new index of ventricular contractility. Am F Cardiol 1977;40:748-53.

20 Suga H, Kitabatake A, Sagawa K. End-systolic pressure determines stroke volume from fixed end-diastolic volume in the isolated canine left ventricle under

contractile state. Circ Res 1979;44:238-49. uecherer HF, Kee LL, Modin G, Cheitlin MD, Schille NB. Echocardiography in serial evaluation of left ventricular systolic and diastolic function: importance of image acquisition, quantitation, and physiologic variability in
clinical and investigational applications. $f \mathrm{Am}$ Soc Echocardiogr 1991;4:203-14.

22 Moye LA, Pfeffer MA, Braunwald E. Rationale, design and baseline characteristics of the survival and ventricular enlargement trial. SAVE Investigators. Am $\mathcal{f}$ Cardiol

23 St John Sutton M, Pfeffer MA, Plappert T, Rouleau JL, Moye LA, Dagenais GR, et al. Quantitative two-dimensional echocardiographic measurements are major predictors of adverse cardiovascular events after acute myocardial infarction. The protective effects of captopril. Circulation 1994;89:68-75.

24 Volpi A, De Vita C, Franziosi MG, et al. Determinants of 6-month mortality in survivors of myocardial infarction after thrombolysis. Results of the Gruppo Italiano per lo Studio della Sopravivenza nell'Infarto Miocardico (GISSI-2) data base. Circulation 1993;88:416-29.

25 Byrd BF III, Wahr D, Wang YS, Bouchard A, Schiller NB Left ventricular mass and volume/mass ratio determined by two-dimensional echocardiography in normal adults. $\mathcal{F}$ Am Coll Cardiol 1985;5:1021.

26 Diethelm L, Simonson JS, Dery R, Gould RG, Schiller NB, Lipton MJ. Determination of left ventricular mass with ultrafast CT and two-dimensional echocardiography. Radiology 1989;171:213-7.

27 Gutman J, Wang YS, Wahr D, Schiller NB. Normal left atrial function determined by 2-dimensional echocardiography. Am $\mathcal{F}$ Cardiol 1983;51:336-40.

28 Kircher B, Abbott AJ, Pau S, Gould RG, Himelman RB, Higgins CB, Lipton MJ. Left atrial volume determination by biplane two dimensional echocardiography: validation by cine computed tomography. Am Heart $\mathcal{f}$ 1991;121: b64-71.

29 Wahr DW, Wang YS, Schiller NB. Left ventricular volin a normal adult population. $\mathcal{F} \mathrm{Am}$ Coll Cardiol 1983;1: in a no $863-8$.

30 Wang Y, Gutman JM, Heilbron D, Wahr D, Schiller NB. Atrial volume in a normal adult population by twodimensional echocardiography. Chest 1984;86:595-601.

31 Mickelson JK, Byrd BF III, Bouchard A, Botvinick EH, Schiller NB. Left ventricular dimensions and mechanics in distance runners. Am Heart $\mathcal{F}$ 1986;112:1251-6.

32 Himelman RB, Chung WS, Chernoff DN, Schiller NB, Hollander $\mathrm{H}$. Cardiac manifestations of human immunodeficiency virus infection: a two-dimensional echocardiographic study. $f$ Am Coll Cardiol 1989;13:1030-6.

33 Massie BM, Schiller NB, Ratshin RA, Parmley WW Mitral-septal separation: new echocardiographic index of left ventricular function. $A m \mathcal{F}$ Cardiol 1977;39:1008-16.

34 Djalaly A, Schiller NB, Poehlmann HW, Arnold S, Gertz EW. Diastolic aortic root motion in left ventricular hypertrophy. Chest 1981;79:442-5.

35 Isaaz K, Munoz del Romeral L, Lee E, Schiller NB. Quantitation of the motion of the cardiac base in norma subjects by Doppler echocardiography. I Am Soc Echocardiogr 1993;6:166-76.

36 Simonson JS, Schiller NB. Descent of the base of the left ventricle: an echocardiographic index of left ventricular 
function. F Am Soc Echocardiogr 1989;2:25-35.

37 Jiang L, Vazquez de Prada JA Handschumacher MD, Vuille $\mathrm{C}$, Guererro $\mathrm{L}$, Picard $\mathrm{MH}$, et al. Quantitative three-dimensional reconstruction of aneurysmal left ventricles. In vitro and in vivo validation. Circulation 1995; 91:222-30.

38 Sapin PM, Schroeder KD, Smith MD, DeMaria AN, King DL. Three-dimensional echocardiographic measurement of left ventricular volume in vitro: comparison with twodimensional echocardiography and cineventriculography. f Am Coll Cardiol 1993;22:1530-7.

39 Pearlman AS. Measurement of left ventricular volume by three-dimensional echocardiography-present promise and potential problems. $\mathcal{F}$ Am Coll Cardiol 1993;22:1538-40.

Siu SC, Rivera JM, Guerrero JL, Handschumacher MD, Lethor JP, Weyman AE, et al. Three-dimensional echocardiography. In vivo validation for left ventricular volume and function. Circulation 1993;88:1715-23.

41 Schroder KM, Sapin PM, King DL, Smith MD, DeMaria AN, et al. Three-dimensional echocardiographic volume computation: in vitro comparison to standard twodimensional echocardiography. $7 \mathrm{Am}$ Soc Echocardiogr 1993;6:467-75.

42 Foster E, Cahalan M K. The search for intelligent quantitation in echocardiography: "eyeball", "trackball" and beyond. F Am Coll Cardiol 1993;22:848-50. 